\title{
Regenerative Technological Research on the Heat Accumulation of Salt Ball Concrete and the Integration of Steam Furnace
}

\author{
Xiujing Song ${ }^{1,}$, , Shengyi Ren ${ }^{2, b}$ \\ ${ }^{1}$ Institute of applied technology , Dalian Ocean University, Dalian, Liaoning, China 116300 \\ ${ }^{2}$ Institute of applied technology, Dalian Ocean University, Dalian, Liaoning, China 116300 \\ a:email:Xincailiao@126.com, bemail:Rewoxing698@126.com
}

\begin{abstract}
Keywords: Molten salt ball; Storage; Steam ovens; Aluminate cement concrete; Integration
Abstract. The device of the heat accumulation of salt ball concrete and the integration of Steam Furnace is composed of dimensional heat pipes, steam room, serpentine lead pipes, tanks, salt ball, aluminate cement concrete, heat pumps and so on. Apply the technology of salt ball concrete re generative furnace with steam integration to solar thermal power generation system can not only reduce the quantity of equipment; lower the cost of the initial investment; but also improve the storage efficiency and reduce the heat loss, and at last achieve the target of sustained and stable electricity day and night.
\end{abstract}

\section{Introduction}

As a limited energy source, fossil fuel could hardly afford long-lasting consumption. And environmental contamination becomes an apparent and serious issue. Countries around the world are developing solar thermal power generation technology, and have already made progress in commercial applications.

When night comes or when the sun is obscured by clouds, solar-thermal power generation system will stop working or produce the phenomenon of frequent start-stop, resulting in the failure of power grid frequency. In order to solve the problems of the sun "intermittent" to "crash" of thermal power generation system, the western developed countries apply the sensible heat storage and latent heat energy storage technologies [1] to the solar-thermal power generation systems, such as the use of solar energy heating concrete to increase its internal energy to store energy for the night use in case of intermittent; Another example is the use of solar energy for double pot [2] to heat (the salt tank and the oil tank ) until the salt melts, to get heat storage through the salt phase change, ready for the power for the use of the night or intermittent. The former is the sensible heat storage technology, the advantage is that the price of the material equipment is relatively low [3], less initial investment, low energy storage efficiency but the disadvantage is that it takes up larger space; The latter is the latent heat energy storage technology, the shortcoming is that the price of the material equipment is relatively high, high energy storage efficiency, it takes up smaller space but the service life of the tank is short. In order to reduce the initial investment cost and improve the efficiency of energy storage, we decide to combine the sensible heat storage and latent heat energy storage to make research on "the technology of the integration of salt ball concrete accumulation of heat and steam furnace ".

\section{Design and materials}

As is shown in Fig.1, the integration device of salt ball concrete accumulation of heat and steam furnace consists of three-dimensional heat pipe, steam room, snake oil fuel tube, oil tank, salt ball, aluminate cement concrete, heat pump, etc. Three-dimensional heat pipe is composed of $\mathrm{N}$ root -welded seamless steel tubes vertical and horizontal three-dimensional grid pipeline shaft. We set the inlet pipe at the bottom of the furnace body and a steam room on the upper part. Steam outlet of three-dimensional grid line to the bottom of the steam room and side and set the outlet steam pipe on the upper part. The inlet pipe of the furnace, the three-dimensional grid line, steam room and steam pipe altogether form a 
systematically channel. Embed $M$ roots coiled tubing in the clearance of the three-dimensional heat pipes. The upper part of the $M$ root snake oil tanks is connected with the oil tank; the bottoms are assembled into an inlet tube out of furnace and connect with the heat pump. Pour salt aluminate cement concrete in between the pipe of the furnace body of the three-dimensional grid and the oil pipeline.

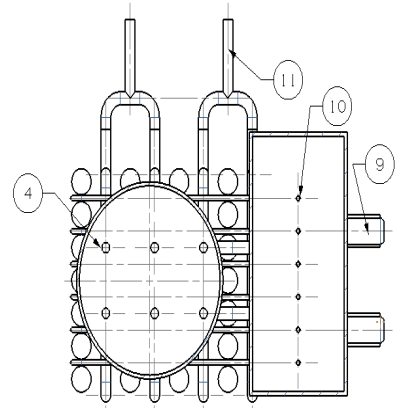

Fig.1: salt ball concrete accumulation of heat and steam furnace sketch

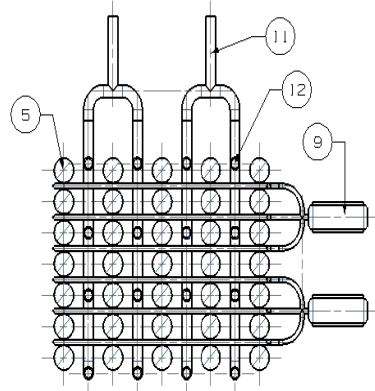

B - B section diagram

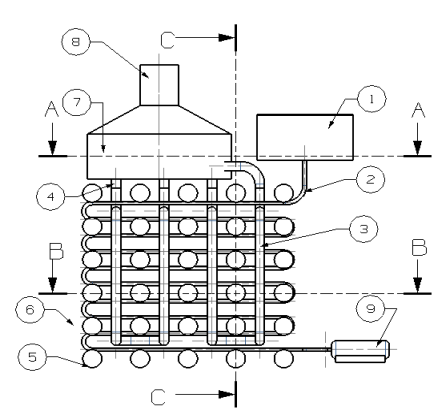

A - A profile

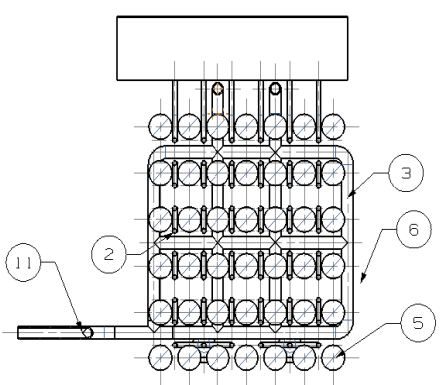

C - C section

1 -the fuel tank; 2 -oil guide tube; 3 - three-dimensional heat pipe;

4 - steam inlet; 5 - salt ball; 6 - aluminate cement concrete; 7 - steam chamber; 8 - export steam pipe; 9 - heat pump; 10 - oil inlet; 11 - feed line; 12 - vertical and horizontal intersection of the three-dimensional grid pipe

Salt ball refers to the mixed molten salt sealed ball, in which potassium nitrate ( melting point 271 ${ }^{\circ} \mathrm{C}$ ), , sodium nitrite (melting point $333^{\circ} \mathrm{C}$ ), sodium nitrate melting point $\left(308^{\circ} \mathrm{C}\right.$ ) are contained. Melt the mixed salt comprises of sodium nitrite $53 \%$, potassium nitrate $40 \%$, sodium nitrate $7 \%$ (melting point $142{ }^{\circ} \mathrm{C}$ ) and fill in the steel ball which has a reserved mouth on the upper part. Weld the sealing mouth reserve to increase the system heat capacity so as to improve security. Aluminate salt ball cement concrete is to use aluminate cement as cementing material $\left(1300 \sim 1400{ }^{\circ} \mathrm{C}\right.$ high temperature resistance), with special salt balls as coarse aggregate, fine aggregate for crushing iron ore, and the right amount of water according to certain proportion, and is characterized by large thermal conductivity, big heat capacity, high temperature resistance and good performance.

\section{The working principle and analysis}

According to Fig.2, connect salt accumulation of heat and steam ball concrete furnace equipment with supporting facilities.

Use the trough type solar collector to concentrate the sun's radiant energy during the day to heat the conduction oil in the set of the hot oil pipeline and use the heat pump and the conductivity oil pipelines to input the oil from the bottom of the coiled tubing, and then flows through the guiding oil tube buried 
in the salt ball concrete cement then flows into the fuel tank which installs a pressure reducing valve, then flows back from the fuel tank to the trough collection heat pipe type solar

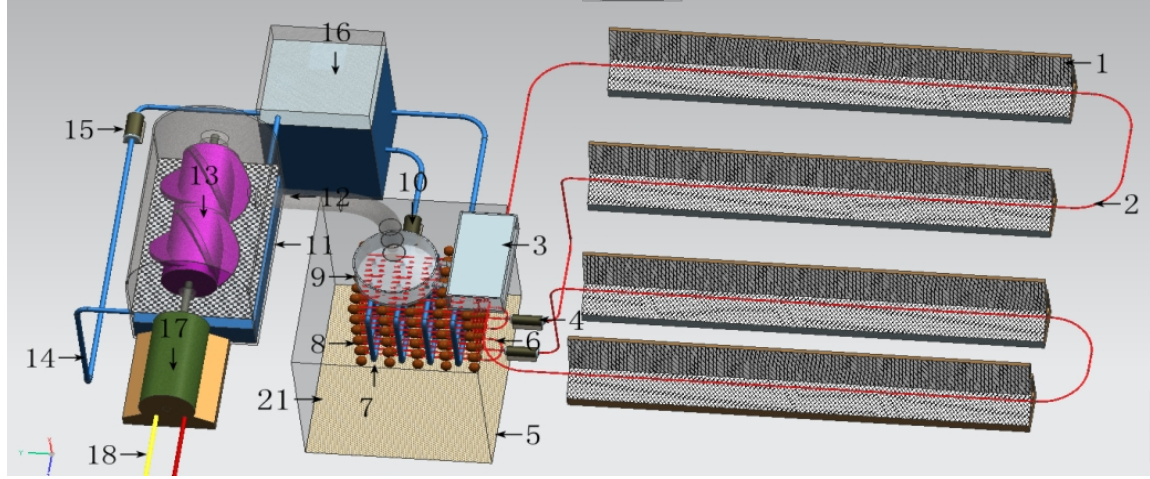

Fig.2: salt accumulation of heat and steam furnace ball concrete application diagram

1 - trough type solar collector; 2 - collection of hot oil pipeline; 3 - Ann has a pressure reducing valve fuel tank; 4 - heat pump; 5 - rock wool; 6 - snake oil; 7 - solid heat pipe; 8 - salt ball; 9 - steam chamber; 10 pumps; 11 - steam turbine generator base; 12 - export steam pipe; 13 - steam wheel; 14 - condensate export pipe; 15 - condensate pumps; 16 and circulation water tank; 17 - generator; 18 - transmission line; 21 - aluminate salts of concrete

collector ,therefore achieves a closed-circuit circulation. In the process of circulation, the heat conduction oil realizes heat exchange through the snake oil conducting pipe as well as the surrounding salt ball concrete cement and the three-dimensional heat pipe. As time flies, the temperature of the salt ball concrete cement keeps on rising, when the temperature reaches the melting point of the mixed salt, it will change the state of solid into the state of gas. It will store more energy by phase change. When the solid state of the mixed salt is completely molten, the temperature will rise again.

As for Power, the automatic control system will issue commands to open the water pump and control the flow to make the water in the water tank go through the inlet pipe at the bottom of the furnace body and inject into the furnace. The water at the bottom of the furnace body is changed into steam utilizing the heat from the surrounding concrete molten salt ball (about $400^{\circ} \mathrm{C}$ ) and three-dimensional heat pipe, the steam from the heat pipe. Drives the generators, at the same time molt the salt due to the release of energy by the liquid solidification into solid state again. When the systematic steam is below the set value, increase the amount of water; when the steam pressure is higher than the set value, decrease it. As the heat exchange continues, the temperature of the salt balls at the bottom of the concrete will lower; water in the furnace body begins to rise gradually. So the steam generator can work round the clock, until a new day arrives, again begins to heat, stores heat generate electricity.

In order to verify the feasibility of the designed method, we made salt ball concrete model of the regenerative heat and steam furnace device (as shown in Fig.3), and the salt concrete heat storage performance has carried on the preliminary test.

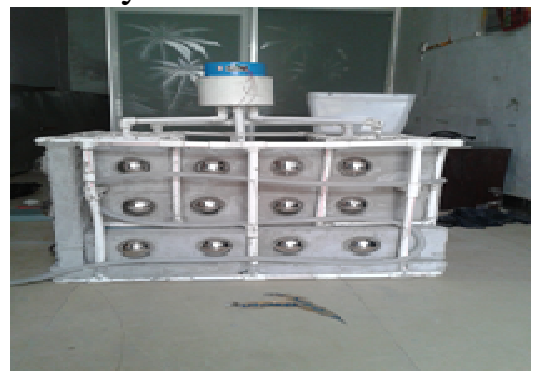

Fig.3: model pictures of the salt concrete heat and steam furnace

When we design the device of the accumulation of heat and steam furnace of the salt ball concrete, we draw lessons from the technologies of international general sensible heat and latent heat storage of 
heat accumulation and other energy storage. The sensible heat storage is to store heat energy through the rising of temperature of specific materials, it is a way of energy storage which is applied in the field of the solar-thermal power generation technology that is most mature and the source of materials is most abundant and the cost is the cheapest . But due to the specific heat capacity of the materials is small while the volume of the heat storage is large; therefore currently it doesn't get extensive application.

Use single aluminate cement concrete, for example, to store energy, due to its small heat capacity of $0.86 \mathrm{~J} /$ (g.), if you want to store the same heat energy, the body of the energy storage will be especially large. When we mention the latent heat energy storage, we mean that we achieve heat energy storage through phase change of the heat storage materials when absorbing heat. Its characteristic is the density of the heat storage is big, they required small body volume of energy storage. Use single mixed nitrate to store energy, for example, because of its large heat capacity of $1.40 \mathrm{~J} /(\mathrm{g}$.), when storing the same heat energy, it needs a smaller heat accumulation body. If we integrate the sensible heat (aluminate cement concrete) with the latent heat (melting mixed salt) and heat storage, the accumulation of heat with the steam generation, when the size of the salt ball and the heat of the salt concrete and steam furnace reaches $1 / 5$ of the total volume, the average heat capacity of the molten salt concrete world is $1.1 \mathrm{~kJ} /(\mathrm{kg} \bullet \mathrm{K})$, the heat loss can be reduced by more than $20 \%$ of the system.

Apply the salt thermal storage and steam oven ball concrete device in the field of solar thermal power generation, it can not only reduce the number of system equipment, but also improve the thermal efficiency. Compared with the technology of today's world-wide double tank (salt tank and oil tank) storage technology, the structure is more reasonable and higher safety performance, longer life as well as more reasonable price.

\section{Conclusions}

$\mathrm{R} \& \mathrm{D}$ of the storage and integration technology of the salt thermal and steam oven ball concrete is the key to solve the question of solar thermal power technology. The development of this technology can not only solve the problem of solar power to generate smoothly and continuously day and night (that matches the existing power grid, strong peaking power generation capacity), but also significantly reduce the cost of the initial investment, and promote the healthy development of the high-temperature solar power technology and intelligent network technology of the new energy to replace traditional fossil fuels gradually. Implementation of this technology can ease the energy crisis, reduce pollution, protect the environment, and promote rapid economic development.

\section{Acknowledgements}

This work was financially supported by Dalian Institute of Vocational and Technical Education Project "Research on developing green skill-based vocational education system " ( DZKY2015B13 ).

Author introduction: Xiujing Song (1965 -), female, associate professor, is mainly engaged in English teaching and research and development of the renewable energy utilization technology E-mail:renwoxing698@126.com. Mobile: 13050558498

\section{References}

[1] Changchun, Xiao Lan, Hongmei Wang etc. Application and Prospect of Thermal Storage Material in the Field of Solar Thermal Power Generation. Journal of New Material Industry, 2012 (7),p. 12-19. In Chinese

[2] Zenghua Tian, Jun Zhang. Design and Research of Double Tank Molten Nitrate Salt For Indirect Thermal Energy Storage Utilizing Trough Solar Power System. Solar Energy , 2009 ( 06 ) ,p29-32. In Chinese 
[3] Jiaoqun Zhu, yuan-yuan Li, Weibing zhou etc. Research and Progress on Solar Thermal Heat and Storage Material. Journal of solar energy, 2009 (6),p. 29-32. In Chinese 